\title{
Longitudinal trajectories of adiponectin and HDL-C levels over a 3-year survey within the anti-aging health checkup system at Tokai University Tokyo Hospital
}

\author{
Chizumi YAMADA ${ }^{1,2}$ Noriaki KISHIMOTO ${ }^{1,2}$ Nobushige YUKUMATSU $^{3}$ \\ Asami TAKedA $^{1,2}$ Tamae OGATA $^{1,2}$ Emiko KIKUCHI $^{1,2}$ Emiko KUROdA $^{1}$ \\ Akira KUBO $^{1}$ Naoaki IsHII $^{2,3}$ Yasuhiro NiSHIZAKI ${ }^{1,2,3}$ \\ ${ }^{I}$ Tokai University Tokyo Hospital \\ ${ }^{2}$ Department of Clinical Health Science, Tokai University School of Medicine \\ ${ }^{3}$ Life Care Center, Graduate School of Medicine, Tokai University
}

\begin{abstract}
Objective To determine if higher adiponectin levels had any beneficial effects on atherosclerosis-related factors, a longitudinal study was conducted involving 77 subjects who underwent annual anti-aging health checks at Tokai University Tokyo Hospital.

Methods The subjects were divided into four groups (Quartile 1, $\mathrm{n}=18$, adiponectin < 5.9 $\mu \mathrm{g} / \mathrm{mL}$; Quartile 2, $\mathrm{n}=$ 19, adiponectin 5.9 to $<8.3 \mu \mathrm{g} / \mathrm{mL}$; Quartile 3, $\mathrm{n}=20$, adiponectin 8.3 to $<11.4 \mu \mathrm{g} / \mathrm{mL}$; Quartile 4 , $\mathrm{n}=20$, adiponectin $>$ $11.4 \mu \mathrm{g} / \mathrm{mL}$ ). The relationship between basal adiponectin level and the following parameters was evaluated: BMI, systolic and diastolic blood pressure, LDL-C, HDL-C, triglycerides, bilateral mean intima-media thickness (IMT) and lifestyle habits (exercise, smoking, drinking and supplement intake) and medical profile (present illness and past history) at baseline and after three years.

Resufts Baseline adiponectin was significantly negatively correlated with baseline BMI, systolic/diastolic BP and triglycerides, and positively correlated with HDL-C. After three years, BMI, diastolic BP and triglycerides showed a significantly negative correlation, and HDL-C showed a significantly positive correlation with baseline adiponectin. The average adiponectin value was significantly elevated after three years in Quartile 4, the highest basal adiponectin group. Baseline HDL-C was higher in Quartile 4 than in the other groups, and significant elevation was observed in HDL-C in Quartile 4 after three years. The percentage of exercisers was significantly increased in the highest basal adiponectin group after three years.

Conclusion Higher basal adiponectin led to further elevation of adiponectin and HDL-C after three years, through an increase in exercise behavior. (HEP. 2015; 42: 444-449.)

Key words Adiponectin, high-density lipoprotein cholesterol (HDL-C), exercise behavior, anti-aging health checkup system
\end{abstract}

\section{INTRODUCTION}

Adiponectin is secreted from adipocytes, and is known to play a protective role against the development of metabolic disorder and atherosclerotic vascular disease. The favorable metabolic action of adiponectin is mediated by alterations in lipid and glucose metabolism. Particularly in lipoprotein metabolism, adiponectin is positively associated with high-density lipoprotein cholesterol (HDL-C) and negatively associated with triglycerides ${ }^{1-3)}$. The adiponectin-lipid relationship can explain, at least in part, the protective role of adiponectin in cardiovascular disease, as well as the anti-inflammatory, anti-atherogenic, vasoprotective and anti-apoptotic properties of adiponectin itself ${ }^{4)}$.

Received: May 8, 2015, Accepted: May 27, 2015

Corresponding author: Yasuhiro Nishizaki

${ }^{1}$ Address; Tokai University Tokai University Tokyo Hospital

1-2-5 Yoyogi, Shibuya-ku, Tokyo 153-0065, Japan

TEL: +81-3-3370-2321, FAX: +81-3-5354-5366

E-mail: y-nishizaki@tokai.ac.jp
Low circulating adiponectin concentrations are found in various pathophysiological conditions such as obesity ${ }^{5,6)}$, metabolic syndrome $^{7)}$, hypertension ${ }^{8)}$, Type 2 diabetes $^{6,9)}$ and cardiovascular disease $^{10,11)}$. Compared to the risk of low adiponectin, there are fewer studies showing the benefit of high adiponectin. A good example linking high adiponectin and successful aging is the centenarian. It has been shown by cross-sectional studies in Japan $^{12)}$ as well as in other nations ${ }^{13,14)}$ that centenarians have significantly higher adiponectin levels compared to their younger counterparts. Arai et al. reported that the mean adiponectin concentration in female centenarians was almost twice as high as that in BMI-matched female controls, and adiponectin showed a significantly positive correlation with HDL- $\mathrm{C}^{12}$. Another study conducted in Poland showed the same results: significantly higher adiponectin concentration in centenarians and a positive association between adiponectin and HDL-C ${ }^{14}$. Octogenarians are also reported to have higher adiponectin concentrations than the corresponding middle-aged controls ${ }^{15}$. The direct correlation between adiponectin and HDL-C was also shown in that report. 
Although both adiponectin and HDL-C are influenced by lifestyle habits, information on lifestyle was lacking in the previous crosssectional studies.

In the present study, we focused on the relationship between adiponectin and HDL-C, and conducted a longitudinal study involving 77 subjects who underwent annual anti-aging health checks at Tokai University Tokyo Hospital for three consecutive years. The aim of this study was to determine if higher adiponectin levels had any beneficial effects on atherosclerosis-related factors, and to investigate any changes in lifestyle habits accounting for the higher adiponectin-related benefits in the study subjects.

\section{SUBJECTS AND METHODS}

\section{Subjects}

Seventy-seven individuals (53 men and 24 women) who underwent annual anti-aging health checks at Tokai University Tokyo Hospital for at least three consecutive years were enrolled in this study. The surveillance period was between June 2006 and October 2013. For subjects who visited the hospital more than four times during the period, the data from the first three times was used for analysis. All subjects gave written informed consent to use their health records for analysis. This study was approved by the Ethics Committee of Tokai University, and was conducted in accordance with the Declaration of Helsinki.

\section{Measurements}

Anthropometric measurements were performed and blood samples were obtained after overnight fasting. Of the measurements included in the anti-aging health check examinations ${ }^{16)}$, the following parameters were used for analysis: adiponectin, BMI, systolic and diastolic blood pressure (BP), low-density lipoprotein cholesterol (LDL-C), HDL-C, triglycerides and bilateral mean intima-media thickness (IMT) values. BP was measured in a sitting position. Serum level of high molecular adiponectin was measured using latex particle-enhanced turbidimetric immunoassay (LTIA $)^{17)}$. The carotid arteries were examined bilaterally at the levels of the common carotid, the bifurcation, and the internal carotid arteries. The IMT was measured by trained sonographers, and mean IMT was calculated and used for analysis. Information about lifestyle habits (exercise, smoking, drinking and supplement intake) and medical profile (present illness and past history) was obtained using a self-administered questionnaire and interview by nurses. Exercise habit is defined as "exercise that causes a slight sweat for $\geq 30$ minutes a time, $\geq 2$ times weekly, for over a year" based on the questionnaire developed for a specific health examination and health guidance. Present illness and past history included any self-reported minor diseases under medical observation/treatment, for example, allergic rhinitis or Helicobacter pylori eradication.

\section{Statistical analysis}

Data is expressed as mean \pm standard deviation (SD). SPSS Statistics (Version 22.0; SPSS Inc.) was used for the statistical analyses. Pearson's correlation coefficient was calculated as a measure of association between baseline adiponectin and the clinical parameters. The subjects were divided into four groups according to the quartiles of baseline adiponectin levels (Quartile $1, \mathrm{n}=18$, adiponectin $<5.9 \mu \mathrm{g} / \mathrm{mL}$; Quartile 2, $\mathrm{n}=19$, adiponectin 5.9 to $<8.3 \mu \mathrm{g} / \mathrm{mL}$; Quartile 3, $\mathrm{n}=20$, adiponectin 8.3 to $<11.4 \mu \mathrm{g} / \mathrm{mL}$; Quartile 4, $\mathrm{n}=20$, adiponectin $>11.4 \mu \mathrm{g} / \mathrm{mL}$ ). Statistical significance for comparisons among the four groups was determined using analysis of variance (ANOVA) and Scheffé's multiple-comparison tests, or $\chi^{2}$ test. A value of $p<$ 0.05 was considered significant.

\section{RESULTS}

The clinical characteristics of the subjects at baseline are shown in Table 1. The study subjects comprised 53 men (68.8\%) and 24 women (31.2\%). The mean age was $63.1 \pm 11.4$ years, and the average interval between the first and third visits was $3.38 \pm 1.22$ years. The average adiponectin level was $9.8 \pm 5.1$ $\mu \mathrm{g} / \mathrm{mL}$. The subjects were not obese on average (BMI $22.8 \pm$ 2.7), and the mean BP, LDL-C, HDL-C, triglycerides and bilateral IMT values were within the normal ranges. Lifestyle habits (exercise, smoking, drinking and supplement intake) and medical profile (present illness and past history) of the study subjects are also shown in Table 1.

The relationship between baseline adiponectin and the clinical parameters was evaluated at baseline and after three years. Baseline adiponectin was significantly negatively correlated with baseline BMI, systolic/diastolic BP and triglycerides, and positively correlated with baseline HDL-C (Table 2). After three years, BMI, diastolic BP and triglycerides still showed a significantly negative correlation, and HDL-C showed a significantly positive correlation with baseline adiponectin (Table 2).

To investigate whether higher adiponectin had any beneficial

Table 1. Background characteristics of the study subjects at baseline

\begin{tabular}{lclr}
\hline \multicolumn{2}{c}{ Clinical data } & Lifestyle habits and medical profile \\
\hline $\begin{array}{l}\text { Age (years) } \\
\begin{array}{l}\text { Adiponectin } \\
(\mu \mathrm{g} / \mathrm{mL})\end{array}\end{array}$ & $63.1 \pm 11.4$ & Exercise & $76.3 \%$ \\
BMI $\left(\mathrm{kg} / \mathrm{m}^{2}\right)$ & $22.8 \pm 2.7$ & Drinking & $12.0 \%$ \\
$\begin{array}{l}\text { Systolic BP } \\
(\mathrm{mmHg})\end{array}$ & $128.1 \pm 20$ & Supplement intake & $50.0 \%$ \\
$\begin{array}{l}\text { Diastolic BP } \\
(\mathrm{mmHg})\end{array}$ & $74.8 \pm 11.8$ & With present illness & $73.7 \%$ \\
$\begin{array}{l}\text { LDL-C } \\
(\mathrm{mg} / \mathrm{dL})\end{array}$ & $124.5 \pm 26.9$ & With past medical history & $67.1 \%$ \\
$\begin{array}{l}\text { HDL-C } \\
(\mathrm{mg} / \mathrm{dL})\end{array}$ & $59.9 \pm 14.1$ & & \\
$\begin{array}{l}\text { Triglyceride } \\
(\mathrm{mg} / \mathrm{dL})\end{array}$ & $115.1 \pm 71.2$ & & \\
$\begin{array}{l}\text { Right mean } \\
\text { IMT }(\mathrm{mm})\end{array}$ & $0.68 \pm 0.14$ & & \\
$\begin{array}{l}\text { Left mean } \\
\text { IMT }(\mathrm{mm})\end{array}$ & $0.74 \pm 0.21$ & & \\
\hline
\end{tabular}

Data are mean $\pm S D$, unless otherwise stated.

BMI, body mass index; BP, blood pressure; LDL-C, low-density lipoprotein cholesterol; HDL-C, high-density lipoprotein cholesterol; IMT, intima-media thickness 
effects on these parameters during the study period, the study population was divided into four groups according to the quartiles of baseline adiponectin levels. Table 3 presents the comparison of clinical parameters across the quartiles of baseline adiponectin levels at baseline and after three years, respectively. Average HDL-C levels significantly increased in order of basal adiponectin quartiles both at baseline and after three years. On the contrary, average triglyceride levels significantly decreased in that

Table 2 Correlations with baseline adiponectin at baseline and after 3 years

\begin{tabular}{lrrrrr}
\hline & \multicolumn{2}{c}{ Baseline } & & \multicolumn{2}{c}{3 years } \\
\cline { 2 - 3 } \cline { 5 - 6 } & \multicolumn{1}{c}{$r$} & \multicolumn{1}{c}{$p$} & & $r$ & $p$ \\
\hline Age & -0.004 & 0.971 & & 0.010 & 0.934 \\
BMI & -0.257 & 0.027 & & -0.343 & 0.003 \\
Systolic BP & -0.268 & 0.020 & & -0.205 & 0.078 \\
Diastolic BP & -0.404 & $<0.001$ & & -0.351 & 0.002 \\
LDL-C & -0.019 & 0.867 & & -0.011 & 0.922 \\
HDL-C & 0.468 & $<0.001$ & & 0.498 & $<0.001$ \\
Triglyceride & -0.354 & 0.002 & & -0.387 & 0.001 \\
Right mean IMT & 0.055 & 0.641 & & 0.001 & 0.993 \\
Left mean IMT & 0.044 & 0.710 & & -0.038 & 0.751 \\
\hline
\end{tabular}

order both at baseline and after three years. Diastolic BP significantly decreased with the increase in basal adiponectin levels, which became unclear three years later. BMI, systolic BP, LDL$\mathrm{C}$, and IMT showed no significant difference by baseline adiponectin level at baseline and after three years. Three-year changes in average adiponectin and HDL-C values across the four groups are visualized in Figure 1, in order to compare the baseline values with the values after three years. Graded increase in average adiponectin levels was clearly observed across the four groups. Most notably, the average adiponectin value increased significantly from $13.12 \mu \mathrm{g} / \mathrm{mL}$ at baseline to $14.68 \mu \mathrm{g} / \mathrm{mL}$ after three years in Quartile 4, the highest basal adiponectin group. There were no such changes in BMI, systolic/diastolic BP and LDL-C. Baseline HDL-C was the highest in Quartile 4 among the four groups, and significant elevation was observed in HDL-C after three years in Quartile 4 from an average value of $69.3 \mathrm{mg} / \mathrm{dL}$ at baseline to $75.5 \mathrm{mg} / \mathrm{dL}$ (Fig. 1). Although a graded decrease was observed in triglycerides, there were no significant differences between the baseline and three-year values in the four groups.

To investigate the influence of lifestyle habits on adiponectin and HDL-C, the percentage of subjects with the following lifestyle habits was examined at baseline and after three years: those who exercised regularly, did not currently smoke, drank alcohol regularly, and took supplements regularly (Table 4). The percent-

Table 3 Comparison of clinical data according to adiponectin quartiles at baseline and after 3 years

\begin{tabular}{|c|c|c|c|c|c|}
\hline Baseline adiponectin $(\mu \mathrm{g} / \mathrm{mL})$ & $\begin{array}{c}\text { Quartile } 1 \\
(2.0-<5.9)\end{array}$ & $\begin{array}{c}\text { Quartile } 2 \\
(5.9-<8.3)\end{array}$ & $\begin{array}{c}\text { Quartile } 3 \\
(8.3-<11.4)\end{array}$ & $\begin{array}{c}\text { Quartile } 4 \\
(11.4-27.8)\end{array}$ & $\begin{array}{c}\text { ANOVA } \\
p\end{array}$ \\
\hline \multicolumn{6}{|l|}{ Baseline } \\
\hline Age (years) & $62.5 \pm 10.8$ & $60.5 \pm 11.7$ & $64.9 \pm 12.1$ & $64.2 \pm 11.2$ & 0.627 \\
\hline Adiponectin $(\mu \mathrm{g} / \mathrm{mL})$ & $6.95 \pm 2.72$ & $8.32 \pm 3.13$ & $10.22 \pm 5.22$ & $13.12 \pm 6.83$ & 0.001 \\
\hline BMI $\left(\mathrm{kg} / \mathrm{m}^{2}\right)$ & $24.0 \pm 2.2$ & $22.8 \pm 2.6$ & $22.5 \pm 2.4$ & $21.8 \pm 3.4$ & 0.105 \\
\hline Systolic BP (mmHg) & $135.2 \pm 20.0$ & $129.7 \pm 18.2$ & $125.1 \pm 20.3$ & $122.8 \pm 20.7$ & 0.268 \\
\hline Diastolic BP (mmHg) & $80.1 \pm 12.9$ & $76.8 \pm 11.0$ & $73.1 \pm 10.9$ & $69.3 \pm 10.5$ & 0.038 \\
\hline LDL-C (mg/dL) & $123.4 \pm 30.7$ & $123.7 \pm 23.5$ & $128.6 \pm 29.9$ & $122.3 \pm 24.7$ & 0.892 \\
\hline HDL-C (mg/dL) & $52.2 \pm 12.9$ & $58.7 \pm 11.3$ & $58.6 \pm 13.2$ & $69.3 \pm 14.0$ & 0.001 \\
\hline Triglyceride (mg/dL) & $167.6 \pm 103.1$ & $117.1 \pm 53.0$ & $100.8 \pm 44.1$ & $80.4 \pm 45.3$ & 0.001 \\
\hline Right mean IMT (mm) & $0.68 \pm 0.11$ & $0.67 \pm 0.14$ & $0.70 \pm 0.18$ & $0.67 \pm 0.14$ & 0.868 \\
\hline Left mean IMT $(\mathrm{mm})$ & $0.71 \pm 0.16$ & $0.74 \pm 0.3$ & $0.79 \pm 0.20$ & $0.71 \pm 0.11$ & 0.647 \\
\hline \multicolumn{6}{|l|}{ After 3 years } \\
\hline Age (years) & $64.8 \pm 10.6$ & $62.6 \pm 11.2$ & $67.7 \pm 12.0$ & $66.5 \pm 11.1$ & 0.514 \\
\hline Years between visits (years) & $3.22 \pm 1.01$ & $3.37 \pm 1.34$ & $3.15 \pm 0.74$ & $3.75 \pm 1.59$ & 0.426 \\
\hline Adiponectin $(\mu \mathrm{g} / \mathrm{mL})$ & $6.53 \pm 2.88$ & $9.68 \pm 4.94$ & $12.55 \pm 8.76$ & $14.68 \pm 8.9$ & 0.004 \\
\hline BMI $\left(\mathrm{kg} / \mathrm{m}^{2}\right)$ & $23.6 \pm 2.8$ & $23.0 \pm 3.1$ & $22.2 \pm 2.3$ & $22.2 \pm 3.0$ & 0.352 \\
\hline Systolic BP (mmHg) & $129.6 \pm 19.8$ & $126.3 \pm 14.6$ & $120.9 \pm 16.6$ & $132 \pm 27.1$ & 0.327 \\
\hline Diastolic BP (mmHg) & $77.1 \pm 10.2$ & $74.8 \pm 12.3$ & $71.5 \pm 9.9$ & $74.9 \pm 13.6$ & 0.495 \\
\hline LDL-C (mg/dL) & $120.8 \pm 27.6$ & $116.6 \pm 28.6$ & $126.6 \pm 28.1$ & $118.4 \pm 25.4$ & 0.687 \\
\hline HDL-C (mg/dL) & $55.4 \pm 12.3$ & $62.2 \pm 15.2$ & $57.8 \pm 14.1$ & $75.5 \pm 14.4$ & $<0.001$ \\
\hline Triglyceride (mg/dL) & $160.6 \pm 118.3$ & $119.1 \pm 58.2$ & $100.3 \pm 51.6$ & $68.0 \pm 16.0$ & 0.001 \\
\hline Right mean IMT (mm) & $0.78 \pm 0.33$ & $0.71 \pm 0.13$ & $0.69 \pm 0.18$ & $0.75 \pm 0.17$ & 0.593 \\
\hline Left mean IMT (mm) & $0.81 \pm 0.21$ & $0.91 \pm 0.36$ & $0.76 \pm 0.23$ & $0.74 \pm 0.20$ & 0.251 \\
\hline
\end{tabular}

Data are mean \pm SD. 

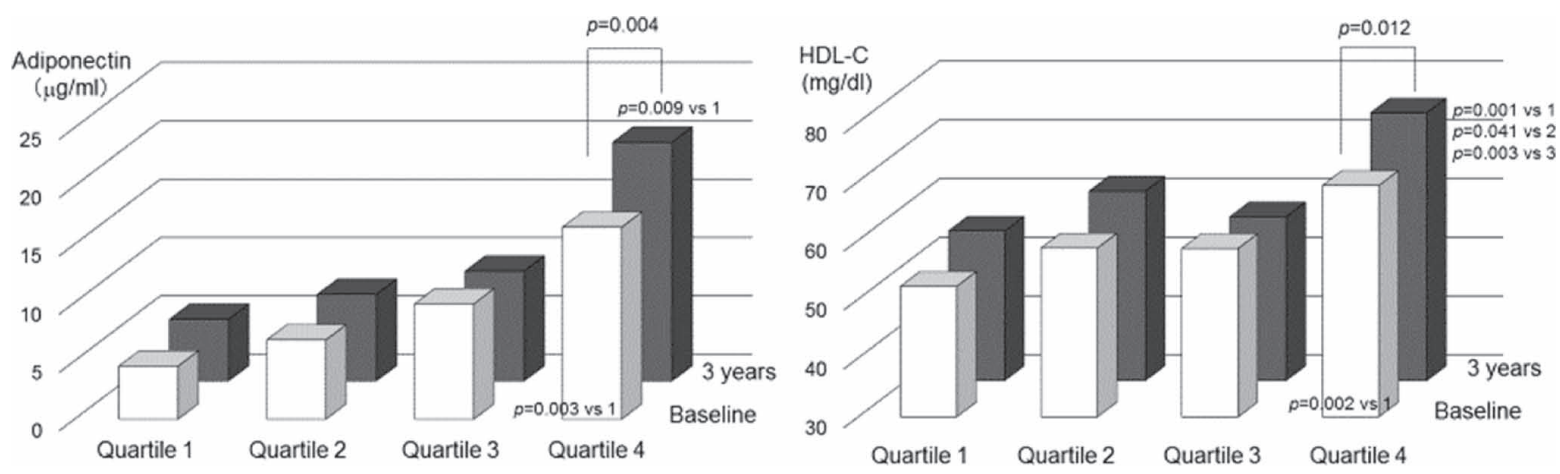

Fig. 1 Three-year changes in average adiponectin and HDL-C values across the quartiles of baseline adiponectin levels.

Table 4 Lifestyle habits and medical profile according to baseline adiponectin quartiles at baseline and after 3 years

\begin{tabular}{|c|c|c|c|c|c|c|c|c|c|c|}
\hline & \multicolumn{5}{|c|}{ Baseline } & \multicolumn{5}{|c|}{3 years } \\
\hline & Quartile 1 & Quartile 2 & Quartile 3 & Quartile 4 & $p$ & Quartile 1 & Quartile 2 & Quartile 3 & Quartile 4 & $p$ \\
\hline Exercise & $77.8 \%$ & $84.2 \%$ & $63.2 \%$ & $80.0 \%$ & 0.449 & $61.1 \%$ & $89.5 \%$ & $63.2 \%$ & $95.0 \%$ & 0.017 \\
\hline Current smoking & $17.6 \%$ & $21.1 \%$ & $5.3 \%$ & $5.0 \%$ & 0.292 & $22.2 \%$ & $31.6 \%$ & $5.3 \%$ & $10.0 \%$ & 0.125 \\
\hline Drinking & $58.8 \%$ & $73.7 \%$ & $42.1 \%$ & $35.0 \%$ & 0.073 & $61.1 \%$ & $52.6 \%$ & $31.6 \%$ & $20.0 \%$ & 0.038 \\
\hline Supplement intake & $66.7 \%$ & $57.9 \%$ & $31.6 \%$ & $45.0 \%$ & 0.154 & $66.7 \%$ & $47.4 \%$ & $47.4 \%$ & $50.0 \%$ & 0.593 \\
\hline With present illness & $66.7 \%$ & $68.4 \%$ & $78.9 \%$ & $80.0 \%$ & 0.703 & $77.8 \%$ & $68.4 \%$ & $84.2 \%$ & $95.0 \%$ & 0.183 \\
\hline With past medical history & $55.6 \%$ & $68.4 \%$ & $68.4 \%$ & $75.0 \%$ & 0.641 & $50.0 \%$ & $63.2 \%$ & $68.4 \%$ & $70.0 \%$ & 0.579 \\
\hline
\end{tabular}

age of exercisers increased significantly in the highest basal adiponectin group after three years, which might have contributed to the elevation of adiponectin and HDL-C. Increased alcohol intake is known to elevate HDL-C, but the percentage of drinkers decreased significantly in Quartile 4 after three years. No significant changes were observed with regard to smoking and supplement intake. The influence of medical profile (present illness and past history) was also examined, and no significant difference was found among the groups during the observation period (Table 4).

\section{DISCUSSION}

In the present study, the longitudinal trajectories of adiponectin and atherosclerosis-related factors were examined over the threeyear survey of the anti-aging health checkup system at Tokai University Tokyo Hospital, and we determined that higher basal adiponectin led to further elevation of adiponectin and HDL-C after three years, possibly through an increase in exercise behavior.

Adiponectin has been shown to increase HDL-C via several mechanisms $^{3)}$ (Fig. 2). Adiponectin increases the hepatic production of apolipoprotein A-I (ApoA-I ${ }^{18)}$, which is the major apolipoprotein of HDL. It enhances ATP-binding cassette transporter A1 (ABCA1) ${ }^{19)}$, which induces HDL assembly via reverse cholesterol transport, through activation of two nuclear receptors, liver $\mathrm{X}$ receptor $\alpha$ and peroxisome proliferator-activated receptor gamma (PPAR $\gamma$ ). It down-regulates the activity of hepatic lipase $(\mathrm{HL})^{20,21)}$, which hydrolyzes triglycerides in large HDL particles (HDL2) to become small HDL particles (HDL3). As HDL2 is the more variable subclass and reflects changes in HDL, decreased

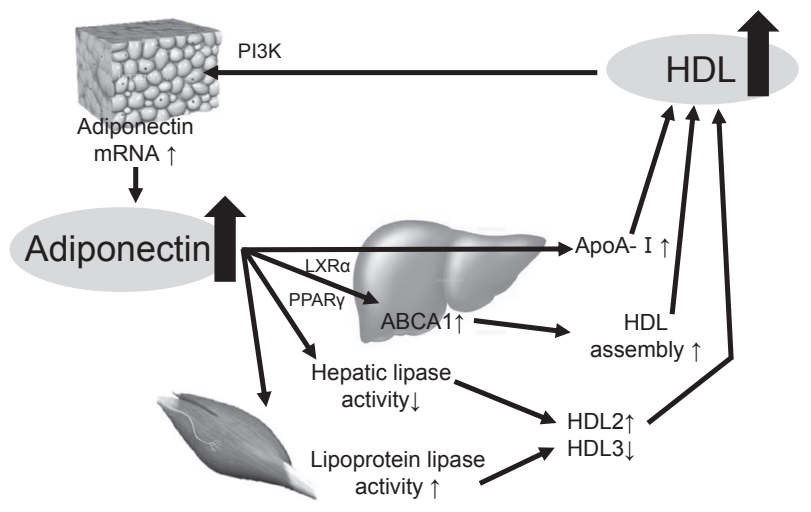

Fig. 2 Interactions between adiponectin and HDL-C metabolism. (Cited and modified from Ref. 3) Adiponectin increases HDL-C via several mechanisms, and HDL-C is considered to increase adiponectin via a phosphatidylinositol-3-kinase (PI3K)mediated pathway. ABCA1, ATP-binding cassette transporter A1; ApoA-I, apolipoprotein A-I; LXR $\alpha$, liver X receptor $\alpha$; $\operatorname{PPAR} \gamma$, peroxisome proliferator-activated receptor gamma.

HL activity by adiponectin can result in HDL-C elevation ${ }^{222}$. Another possible mechanism is adiponectin-induced activation of lipoprotein lipase (LPL) ${ }^{23}$. LPL increases the hydrolyzation of triglycerides in very-low-density lipoprotein (VLDL) particles, reducing the transfer of triglycerides to HDL and rendering HDL particles triglyceride-poor. These HDL particles are not a good substrate for HL lipolysis, which results in the formation of larger HDL2 particles that show reduced renal clearance and thus give rise to an increase in HDL-C. Conversely, HDL-induced upregulation of adiponectin has also been demonstrated. In rodents, it has been shown that HDL induced an increase in the production 
of adiponectin from adipose tissue in a phosphatidylinositol3-kinase (PI3K)-dependent manner ${ }^{24)}$ (Fig. 2) and thereby could cause a rise in circulating adiponectin.

Adiponectin and HDL-C are both increased by exercise ${ }^{25,26)}$. Reports from a few intervention trials involving obese subjects with or without glucose intolerance revealed that both adiponectin and HDL-C were increased by intensive exercise and diet programs targeting $7 \%$ weight loss ${ }^{27-29)}$. However, an increase in HDL-C was not observed through weight loss by only a hypocaloric, low-fat diet without exercise ${ }^{30}$, suggesting the importance of exercise for increasing both adiponectin and HDL-C. In our study, significant elevation was observed in both adiponectin and HDL-C after three years in the highest baseline adiponectin group, in which the percentage of exercisers was significantly increased. Alcohol has been shown to increase adiponectin as well as HDL-C by systematic review and meta-analysis ${ }^{31}$, but alcohol had little involvement in the elevation of adiponectin and HDL-C in this study because the percentage of drinkers was significantly decreased in that group after three years. Smoking is known to reduce HDL-C concentration ${ }^{32}$. The percentage of smokers in that group slightly increased, though not significantly, after three years, but this is of little relevance to the increase in HDL-C. Taken together, we consider that higher basal adiponectin led to further elevation of adiponectin and HDL-C after three years, possibly through an increase in exercise behavior.

Our study has some limitations. First, our subjects who annually undergo anti-aging health checks at Tokai University Tokyo Hospital are considered to be more wealthy and health-conscious than ordinary people, and therefore the results of this study may not be applicable to the general population. In Japan, adiponectin concentration of $<4.0 \mu \mathrm{g} / \mathrm{mL}$ is established as the lower limit from the aspect of metabolic syndrome by Ryo et $a l^{7}$. They reported that hypoadiponectinemia $(<4.0 \mu \mathrm{g} / \mathrm{mL})$ was observed in $18.9 \%$ of 661 subjects. However, the prevalence of hypoadiponectinemia was only $6.5 \%$ in our study. As our subjects had relatively higher adiponectin concentrations as a whole, the characteristics of hyperadiponectinemia may stand out more clearly in our study. Second, as lifestyle habits and medical profile were assessed only by presence or absence, we could not take other important information into consideration. Exercise intensity, frequency, duration or energy expenditure were not accurately evaluated in this study. Dietary information was not obtained. We could not exclude subjects who were receiving lipid-lowering treatment. Moreover, as there was no change in BMI, body composition was expected to be measured, ideally to see whether fat mass changed during the observation period. Third, although epidemiologic studies have consistently shown that HDL-C is inversely associated with cardiovascular risk independent of other atherogenic lipoproteins, it remains controversial whether increasing HDL-C level serves as a protective factor. Evidence from pharmacologic trials directed at increasing HDL-C levels by cholesterol ester transfer protein (CETP) inhibition ${ }^{33)}$ and analyses of genetically high HDL-C people ${ }^{34)}$ have not always shown beneficial effects on clinical outcome. The consensus in this field so far is that improved HDL function, not absolute HDL-C level, may be crucial in the modulation of cardiovascular risk, but HDL function was not measured in our study. Finally, the protective role of adiponectin against cardiovascular disease is controversial. There are some studies reporting that elevated serum levels of total adiponectin were associated with a lower risk of coronary heart disease ${ }^{35,36)}$. The results from the Baltimore Longitudinal Study of Aging revealed that there was no significant difference between participants who lived to at least 90 years of age and individuals who died in their seventies in terms of adiponectin level measured at age $58-70$ years $^{37)}$. On the other hand, there is some data showing an increased risk of all-cause and cardiovascular mortality ${ }^{38,39)}$. In any case, the three-year period was too short to observe even an early carotid arteriosclerotic change, and it will be necessary to wait for the results of a long-term study that is currently under way.

In conclusion, the present study has shown that higher basal adiponectin led to further elevation of adiponectin and HDL-C after three years, possibly through an increase in exercise behavior. Higher adiponectin and HDL-C levels are potentially expected to be protective factors against cardiovascular disease, both of which can be increased by exercise. As a three-year period is too short to observe even an early carotid arteriosclerotic change, this study will be continued until definite conclusions are reached.

\section{ACKNOWLEDGEMENTS}

This study was supported, in part, by a Grant-in-Aid for Scientific Research (C) to YN (25350855) from the Ministry of Education, Culture, Sports, Science and Technology, Japan.

The authors state that they have no conflicts of interest (COI).

\section{REFERENCES}

1) Yamamoto $Y$, Hirose $H$, Saito I, Tomita M, Taniyama M, Matsubara K, et al. Correlation of the adipocyte-derived protein adiponectin with insulin resistance index and serum high-density lipoprotein-cholesterol, independen of body mass index, in the Japanese population. Clin Sci (Lond) 2002; 103: 137-42.

2) Matsubara M, Maruoka S, Katayose S. Decreased plasma adiponectin concentrations in women with dyslipidemia. J Clin Endocrinol Metab 2002; 87: 2764-9.

3) Christou GA, Kiortsis DN. Adiponectin and lipoprotein metabolism. Obes Rev 2013; 14: 939-49.

4) Goldstein BJ, Scalia RG, Ma XL. Protective vascular and myocardial effects of adiponectin. Nat Clin Pract Cardiovasc Med 2009; 6: 27-35.

5) Arita Y, Kihara S, Ouchi N, Takahashi M, Maeda K, Miyagawa J, et al. Paradoxical decrease of an adipose-specific protein, adiponectin, in obesity. Biochem Biophys Res Commun 1999; 257: 79-83.

6) Weyer C, Funahashi T, Tanaka S, Hotta K, Matsuzawa Y, Pratley RE, et al. Hypoadiponectinemia in obesity and type 2 diabetes: close association with insulin resistance and hyperinsulinemia. $\mathrm{J}$ Clin Endocrinol Metab 2001; 86: 1930-5.

7) Ryo M, Nakamura T, Kihara S, Kumada M, Shibazaki S, Takahashi M, et al. Adiponectin as a biomarker of the metabolic syndrome. Circ J 2004; 68: 975-81.

8) Adamczak M, Wiecek A, Funahashi T, Chudek J, Kokot F, Matsuzawa Y. Decreased plasma adiponectin concentration in 
patients with essential hypertension. Am J Hypertens 2003; 16: $72-5$.

9) Snijder MB, Heine RJ, Seidell JC, Bouter LM, Stehouwer CD, Nijpels G, et al. Associations of adiponectin levels with incident impaired glucose metabolism and type 2 diabetes in older men and women: the Hoorn study. Diabetes Care 2006; 29: 2498-503.

10) Kumada M, Kihara S, Sumitsuji $S$, Kawamoto $T$, Matsumoto $S$, Ouchi N, et al. Association of hypoadiponectinemia with coronary artery disease in men. Arterioscler Thromb Vasc Biol 2003; 23: 85-9.

11) Nakamura Y, Shimada K, Fukuda D, Shimada $Y$, Ehara S, Hirose $\mathrm{M}$, et al. Implications of plasma concentrations of adiponectin in patients with coronary artery disease. Heart 2004; 90: 528-33.

12) Arai Y, Nakazawa S, Kojima T, Takayama M, Ebihara Y, Shimizu $\mathrm{K}$, et al. High adiponectin concentration and its role for longevity in female centenarians. Geriatr Gerontol Int 2006; 6: 32-6.

13) Bik W, Baranowska-Bik A, Wolinska-Witort E, Martynska L, Chmielowska M, Szybinska A, et al. The relationship between adiponectin levels and metabolic status in centenarian, early elderly, young and obese women. Neuro Endocrinol Lett 2006; 27: 493-500.

14) Bik W, Baranowska-Bik A, Wolinska-Witort E, Kalisz M, Broczek $\mathrm{K}$, Mossakowska M, et al. Assessment of adiponectin and its isoforms in Polish centenarians. Exp Gerontol 2013; 48: 401-7.

15) Graessler J, Gruber M, Radke RB, Kopprasch S, Schwarz PE, Kamke W, et al. Type 2 diabetes in octogenarians is associated with decreased low molecular weight adiponectin. Gerontology 2011; 57: 316-26.

16) Nishizaki Y, Kubo A, Kuwahira I, Kuroda E, Nigou N, Sueno T, et al. Anti-aging health check-up system - For the prevention of potentially progress aging related disadvantageous changes in elderly. Health Evaluation and Promotion 2012; 39: 549-57.

17) Nishimura A, Sawai T. Determination of adiponectin in serum using a latex particle-enhanced turbidimetric immunoassay with an automated analyzer. Clin Chim Acta 2006; 371: 163-8.

18) Vergès B, Petit JM, Duvillard L, Dautin G, Florentin E, Galland $\mathrm{F}$, et al. Adiponectin is an important determinant of apoA-I catabolism. Arterioscler Thromb Vasc Biol 2006; 26: 1364-9.

19) Oku H, Matsuura F, Koseki M, Sandoval JC, Yuasa-Kawase M, Tsubakio-Yamamoto K, et al. Adiponectin deficiency suppresses ABCA1 expression and ApoA-I synthesis in the liver. FEBS Lett 2007; 581: 5029-33.

20) Schneider JG, von Eynatten M, Schiekofer S, Nawroth PP, Dugi KA. Low plasma adiponectin levels are associated with increased hepatic lipase activity in vivo. Diabetes Care 2005; 28: 2181-6.

21) Clarenbach JJ, Vega GL, Adams-Huet B, Considine RV, Ricks M, Sumner AE. Variability in postheparin hepatic lipase activity is associated with plasma adiponectin levels in African Americans. J Investig Med 2007; 55: 187-94.

22) Tsubakio-Yamamoto $K$, Sugimoto $T$, Nishida $M$, Okano R, Monden Y, Kitazume-Taneike R, et al. Serum adiponectin level is correlated with the size of HDL and LDL particles determined by high performance liquid chromatography. Metabolism 2012; 61: 1763-70.

23) von Eynatten M, Schneider JG, Humpert PM, Rudofsky G, Schmidt N, Barosch P, et al. Decreased plasma lipoprotein lipase in hypoadiponectinemia: an association independent of systemic inflammation and insulin resistance. Diabetes Care 2004; 27 : 2925-9.
24) Van Linthout S, Foryst-Ludwig A, Spillmann F, Peng J, Feng Y, Meloni M, et al. Impact of HDL on adipose tissue metabolism and adiponectin expression. Atherosclerosis 2010; 210: 438-44.

25) $\mathrm{Vu}$ V, Riddell MC, Sweeney G. Circulating adiponectin and adiponectin receptor expression in skeletal muscle: effects of exercise. Diabetes Metab Res Rev 2007; 23: 600-11.

26) Blazek A, Rutsky J, Osei K, Maiseyeu A, Rajagopalan S. Exercise-mediated changes in high-density lipoprotein: impact on form and function. Am Heart J 2013; 166: 392-400.

27) Esposito K, Pontillo A, Di Palo C, Giugliano G, Masella M, Marfella R, et al. Effect of weight loss and lifestyle changes on vascular inflammatory markers in obese women: a randomized trial. JAMA 2003; 289: 1799-804.

28) Mather KJ, Funahashi T, Matsuzawa Y, Edelstein S, Bray GA, Kahn SE, et al. Adiponectin, change in adiponectin, and progression to diabetes in the Diabetes Prevention Program. Diabetes 2008; 57: 980-6.

29) Belalcazar LM, Lang W, Haffner SM, Hoogeveen RC, Pi-Sunyer FX, Schwenke DC, et al. Adiponectin and the mediation of HDLcholesterol change with improved lifestyle: the Look AHEAD Study. J Lipid Res 2012; 53: 2726-33.

30) Ng TW, Watts GF, Barrett PH, Rye KA, Chan DC. Effect of weight loss on LDL and HDL kinetics in the metabolic syndrome: associations with changes in plasma retinol-binding protein-4 and adiponectin levels. Diabetes Care 2007; 30: 2945-50.

31) Brien SE, Ronksley PE, Turner BJ, Mukamal KJ, Ghali WA. Effect of alcohol consumption on biological markers associated with risk of coronary heart disease: systematic review and metaanalysis of interventional studies. BMJ 2011; 342: d636. doi: 10.1136/bmj.d636.

32) Khurana M, Sharma D, Khandelwal PD. Lipid profile in smokers and tobacco chewers - a comparative study. J Assoc Physicians India 2000; 48: 895-7.

33) Rader DJ, deGoma EM. Future of cholesteryl ester transfer protein inhibitors. Annu Rev Med 2014; 65: 385-403.

34) Thompson A, Di Angelantonio E, Sarwar N, Erqou S, Saleheen D, Dullaart RP, et al. Association of cholesteryl ester transfer protein genotypes with CETP mass and activity, lipid levels, and coronary risk. JAMA 2008; 299: 2777-88.

35) Frystyk J, Berne C, Berglund L, Jensevik K, Flyvbjerg A, Zethelius B. Serum adiponectin is a predictor of coronary heart disease: a population-based 10-year follow-up study in elderly men. J Clin Endocrinol Metab 2007; 92: 571-6.

36) Laughlin GA, Barrett-Connor E, May S, Langenberg C. Association of adiponectin with coronary heart disease and mortality: the Rancho Bernardo study. Am J Epidemiol 2007; 165: 164-74.

37) Stenholm S, Metter EJ, Roth GS, Ingram DK, Mattison JA, Taub $\mathrm{DD}$, et al. Relationship between plasma ghrelin, insulin, leptin, interleukin 6, adiponectin, testosterone and longevity in the Baltimore Longitudinal Study of Aging. Aging Clin Exp Res 2011; 23: $153-8$.

38) annamethee SG, Whincup PH, Lennon L, Sattar N. Circulating adiponectin levels and mortality in elderly men with and without cardiovascular disease and heart failure. Arch Intern Med 2007; 167: 1510-7.

39) Poehls J, Wassel CL, Harris TB, Havel PJ, Swarbrick MM, Cummings SR, et al. Association of adiponectin with mortality in older adults: the Health, Aging, and Body Composition Study. Diabetologia 2009; 52: 591-5. 